\title{
Association between dietary intake, physical activity and stress level with constipation among undergraduate students
}

\author{
Nor Baizura Md. Yusop \& Nor Qubbul Ain Mohamed Yasin \\ Department of Dietetics, Faculty of Medicine and Health Sciences, Universiti Putra \\ Malaysia, Selangor, Malaysia.
}

\begin{abstract}
Introduction: Constipation is one of the most common health problems among university students. This study aims to determine the association between sociodemographic characteristics, dietary intake, physical activity, and stress level with constipation among undergraduate students. Methods: The study was a crosssectional study and the participants comprised of 140 undergraduate students (27.9\% males and $72.1 \%$ females). A 3-day dietary record was obtained to determine energy, fibre and fluid intakes, while physical activity was determined using the International Physical Activity Questionnaire. Stress level and constipation were assessed using the Cohen's Perceived Stress Scale and Agachan's Constipation Score System Questionnaire, respectively. Data were analysed using IBM SPSS Statistics version 23. Multivariate linear regression analysis was done to determine factors that were associated with constipation. Results: Mean age of the participants was $20.9 \pm 1.5$ years old and majority were third year students $(32.1 \%)$. Mean intakes of energy, dietary fibre, and fluids per day were $1567 \pm 438 \mathrm{kcal}, 5.6 \pm 3.5 \mathrm{~g}$, and $2301 \pm 946 \mathrm{ml}$, respectively. The median score for physical activity was 1135.5 METminutes/week. Most of the participants $(77.1 \%)$ had a high or a very high stress level and $64.3 \%$ had slight constipation. Age, dietary fibre, fluid, energy, and perceived stress scale explained a significant amount of the variance in the occurrence of constipation $\left[F(6.133)=16.373, p<0.001, R^{2}=0.425, R^{2}{ }_{\text {Adjusted }}=0.399\right]$. Conclusion: Age, energy, fluid and fibre intakes, as well as perceived stress were factors that were associated with constipation among undergraduate students. Therefore, undergraduate students should be encouraged to practise a healthy lifestyle to modify these identified risk factors.
\end{abstract}

Keywords: Constipation, energy intake, dietary fibre, fluid intake

\section{INTRODUCTION}

Constipation is one of the most common gastrointestinal (GI) disorders encountered in clinical practice and is defined as having three or fewer times of bowel movements per week. Patients with constipation may experience prolonged, incomplete, difficult and/or painful defecation, which can greatly affect their quality of life. Furthermore, this straining during bowel movement may also lead to the development of haemorrhoids, which can cause further pain, itchiness or even bleeding

\footnotetext{
*Corresponding author: Nor Baizura Md. Yusop, PhD

Department of Dietetics, Faculty of Medicine and Health Sciences, Universiti Putra Malaysia, 43400 Serdang, Malaysia

Tel: (6)013-2094595; Email: norbaizura@upm.edu.my doi: https://doi.org/10.31246/mjn-2019-0099
} 
during bowel movement (American Gastroenterological Association, 2013). In Asia, about $10 \%$ to $98.4 \%$ of adults have experienced symptoms of constipation. The core symptoms of constipation can be further divided into 'straining' that are experienced by $82.8 \%$ of adults, 'lumpy and hard stool' (74.2\%), and 'incomplete evacuation' in another $68.1 \%$ of adults (Patimah et al., 2017).

Utilising the Rome II criteria, Karakaya et al. (2015) reported that the prevalence of constipation among university students was $20.6 \%$. Meanwhile, Lim et al. (2016) documented that the prevalence of functional constipation among undergraduate students was $16.2 \%$ based on the Rome III criteria and it was recognised as one of the most common health problems among undergraduate students. Less intakes of energy, dietary fibre and water, and physical inactivity, as well as having stress were found as risk factors for constipation in another study (Leung et al., 2011). Consumption of lower calories for long term may also decrease the stimulation of colonic motility as limited amount of food passes from the stomach into the upper part of the small intestine (Malone \& Thavamani, 2020).

Furthermore, undergraduate students are known for practising undesirable health-related behavioural habits such as increased consumption of unhealthy foods since they are living away from home. When they stay away from their family and indulge in eating out, they often feel relieved when all their food desires can be easily satisfied. These habits are mostly attributed to a higher consumption of high caloric snacks and fast foods, as well as a lower intake of fruits and vegetables (Sogari et al., 2018). Studies found that only $11 \%$ of the undergraduate students fulfilled the recommendation of taking 20 - $30 \mathrm{~g}$ of fibre per day (Koo et al., 2019; NCCFN, 2017). The latest findings from the National Health and Morbidity Survey (NHMS) in 2019 showed that $95 \%$ of Malaysian adults do not consume enough fruits, vegetables and plain water (IPH, 2020). Inadequacy of dietary fibre and plain water intakes can worsen the symptoms of constipation. Besides insufficient dietary fibre intake, it was also found that inadequate intake of fluid is strongly associated with aggravated constipation symptoms (Mazlyn et al., 2013).

A study found that majority of youths have a moderate level of active lifestyle (Salamudin \& Harun, 2013). NHMS 2019 also reported that one in four adults are not physically active (IPH, 2020). Youths aged 21 years old and below are more active than other age categories. However, above this age category, youths have a reduced physical activity level. This may be due to time constraint which makes them spend less time on exercising and more time revising their studies (Salamudin \& Harun, 2013). It was identified that undergraduate students pursuing the medical programme had a lower physical activity level (26\%) as compared to other academic programmes. It is very important to be more physically active as it will reduce the risk of chronic constipation (Chang et al., 2015).

A study conducted by Gan et al. (2011) found that $21.6 \%$ of university students experience moderate to high levels of stress. Stress can lead to serious health issues in many ways. It was found that unhealthy dietary pattern often occurs in female students who are stressed. They tend to consume more energy dense foods such as high sugary food because they believe it will reduce their stress levels (Mikolajczyk, Ansari \& Maxwell, 2009). The brain and gut work very closely together, thus any disturbances in mental capability due to stress will invariably disrupt the gastrointestinal tract function, which 
may then lead to constipation (Lingu et al., 2012).

There are several local studies looking at the factors associated with constipation (Patimah et al., 2017). However, there are limited number of studies that focus on constipation among university students. Therefore, the purpose of this study was to determine the association between sociodemographic characteristics, dietary intake, physical activity, and stress level with constipation among undergraduate students. The study offered an opportunity to those with constipation to rectify this chronic health problem that may have arisen as they grow older. Through this study, more knowledge on the factors that can contribute to constipation can be acquired in hope that constipation can be prevented at an early stage.

\section{MATERIALS AND METHODS}

A cross-sectional study was conducted among undergraduate students to determine the association between socio-demographic characteristics, dietary intake, physical activity, and stress level with constipation. A total of 140 participants were recruited by using the cluster sampling method. There are sixteen faculties in UPM and two out of sixteen faculties were randomly selected. The two participating faculties were the Faculty of Medicine and Health Sciences and the Faculty of Computer Science and Information Technology. In each participating faculty, two academic programmes were further randomly selected. All of the undergraduate students in the selected academic programmes were invited to participate in this study. Lastly, the participants were recruited by using inclusion and exclusion criteria. The inclusion criteria for this study were undergraduate students of both genders and all ethnic groups. International students, postgraduate students, those with physical disabilities, and were pregnant during the time of enrolment were excluded. The total participants from the Faculty of Medicine and Health Sciences were 92 participants, meanwhile from the Faculty of Computer Science and Information Technology were 48 participants. Data collection was conducted from December 2016 to February 2017. The sample size of the study was computed using Epi Info version 7 by considering the following assumptions: the prevalence of constipation among university students was $20.6 \%$ (Karakaya et al., 2015), a $95 \%$ level of significance, and a power of $80 \%$. Finally, the sample size of 127 was obtained with an addition of a $10 \%$ nonresponse rate.

Socio-demographic characteristics of the participants such as age, sex, ethnicity, year of study, and monthly food expenditure (RM) were captured. Dietary intake was assessed by using a three-day dietary record (two weekdays and one weekend). The three-day dietary record was prepared in the form of a booklet and was given during the interview session. During the interview session, the researcher guided the participants on how to estimate the portion size and quantity of foods consumed (Suzana et al., 2009). After three days, the researcher contacted the participants to collect and verify the records. Participants were told to record all foods and beverages intake including cooking methods and brand names of processed foods. The Nutritionist Pro software and information from the Malaysian Food Composition Table (Tee et al., 1997) and the Food Composition Guide Singapore (Health Promotion Board Singapore, 2003) were used in the analysis. Data on total energy, fibre and fluid intakes were retrieved from the analysis. 
Short form version of the International Physical Activity Questionnaire (IPAQ) was used to assess the participants' physical activity level for the past seven days. IPAQ short form version comprised of seven questions, which included physical activities such as walking, moderate-intensity and vigorousintensity physical activities. The physical activity levels were categorised into three levels, which were low, moderate and high. The formula used was: MET level $\times$ minutes of activity $\times$ frequency per week (International Physical Activity Questionnaire Group, 2002).

Stress level was assessed by using the Cohen's Perceived Stress Scale (PSS), which consisted of ten items. The participants were asked about their feelings and thoughts during the past one month and they were asked to answer these questions quickly without thinking about the actual number of times they have experienced it. A five-point Likert scale was used to rate the responses, ranging from never (0), almost never (1), sometimes (2), fairly often (3) to very often (4). Positively worded items at numbers 4, 5, 7 and 8 were scored inversely $(0=4$, $1=3,2=2,3=1,4=0$ ). Higher scores were associated with higher levels of perceived stress. The perceived stress level was grouped into "very low" (0-7 marks), "low" (8-11 marks), "average" (12-15 marks), "high" (16-20 marks), and "very high" ( $\geq 21$ marks).

The Agachan's Constipation Score System Questionnaire contains eight items (frequency of bowel movements; difficulty in evacuation; completeness of evacuation; abdominal pain; time per attempt; type of assistance; number of unsuccessful attempts for evacuation per 24 hours; and duration of constipation). A five-point Likert scale was used to rate the seven items in a range of 0 (none of the time) to 4 (all of the time), and one item in the range of 0 to 2 . The total score ranged from 0 to 30 , which was then grouped into "none" (<5 marks), "slight" (5-9 marks), "moderate" (10-14 marks), and "severe" ( $\geq 15$ marks). The severity of constipation increases with a higher total score (Ng et al., 2016).

Data collected were analysed by using the IBM SPSS Statistics version 23 with the significance level set at $p<0.05$. Univariate analysis was used to analyse all descriptive data. The results for categorical variables were presented as frequencies and percentages, while the results for continuous variables were presented as mean and standard deviation. Multivariate linear regression analysis using stepwise method was done to identify the factors associated with constipation.

\section{Ethics statement}

Prior to the commencement of the study, ethical approval was obtained from the Ethics Committee for Research Involving Human Subjects, Universiti Putra Malaysia [reference number: UPM/TNCPI/RMC/1.4.18.2 (JKEUPM)]. Permission for data collection was also obtained from the Faculty of Computer Science and Information Technology, UPM. Prior to data collection, participant information sheets were distributed to the participants and informed consent was obtained.

\section{RESULTS}

Participant's socio-demographic characteristics are presented in Table 1. Mean age of the participants was $20.9 \pm 1.5$ years old and majority were females (72.1\%). Majority (63.6\%) of them were Malays and third year students $(32.1 \%)$. More than half of the participants (70.0\%) spent about RM100 to RM300 on food, while the remaining participants $(30.0 \%)$ were living with a higher monthly food expenditure of between RM301 to RM600. The mean intakes of energy, dietary fibre, and fluids 
per day were $1567 \pm 438 \mathrm{kcal}, 5.6 \pm 3.5 \mathrm{~g}$, and $2301 \pm 946 \mathrm{ml}$, respectively. The median score and interquartile range for physical activity among the participants were 1135.5 and 1796 MET-minutes/ week, respectively. Majority of the participants $(60.7 \%)$ were considered as having a moderate physical activity level. It was found that most of the participants $(77.1 \%)$ had a high or a very high stress level and $64.3 \%$ had slight constipation.

Table 2 shows the mean energy, fibre and fluid intakes of the participants.

Table 1. Socio-demographic characteristics, dietary intake, physical activity, stress level, and constipation of participants

\begin{tabular}{|c|c|c|c|}
\hline Characteristics & $n(\%)$ & Mean $\pm S D$ & Range \\
\hline \multicolumn{4}{|l|}{ Socio-demographic characteristics } \\
\hline Age (years) & & $20.9 \pm 1.5$ & \\
\hline \multicolumn{4}{|l|}{ Sex } \\
\hline Male & 39 (27.9) & & \\
\hline Female & $101(72.1)$ & & \\
\hline \multicolumn{4}{|l|}{ Ethnicity } \\
\hline Malay & 89 (63.6) & & \\
\hline Chinese & $41(29.3)$ & & \\
\hline Indian & $10(7.1)$ & & \\
\hline \multicolumn{4}{|l|}{ Year of study } \\
\hline First year & $40(28.6)$ & & \\
\hline Second year & $38(27.1)$ & & \\
\hline Third year & $45(32.1)$ & & \\
\hline Fourth year & $17(12.1)$ & & \\
\hline Monthly food expenditure & & $287.8 \pm 108.6$ & $100.00-600.00$ \\
\hline RM $100-300(\$ 24.57-73.62)$ & $98(70.0)$ & $70.7 \pm 26.7$ & \\
\hline RM $301-600$ (\$ $73.62-147.43)$ & $42(30.0)$ & & \\
\hline \multicolumn{4}{|l|}{ Dietary intake } \\
\hline Energy (kcal/day) & & $1567 \pm 438$ & \\
\hline Dietary fibre intake (g/day) & & $5.6 \pm 3.5$ & \\
\hline Fluid intake (ml/day) & & $2301 \pm 946$ & \\
\hline \multicolumn{4}{|l|}{ Physical activity } \\
\hline Total score (MET-minutes/week) & & $1135.5^{+}$ & \\
\hline Low $(<600)$ & $32(22.9)$ & & \\
\hline Moderate (600-2999) & $85(60.7)$ & & \\
\hline High $(\geq 3000)$ & $23(16.4)$ & & \\
\hline Stress level & & $19.9 \pm 5.4$ & \\
\hline Lowest (0-7) & $0(0)$ & & \\
\hline Low $(0-11)$ & $7(5.0)$ & & \\
\hline Average (12-15) & 25 (17.9) & & \\
\hline High (16-20) & $49(35.0)$ & & \\
\hline Very high $(\geq 21)$ & $59(42.1)$ & & \\
\hline \multicolumn{4}{|l|}{ Constipation } \\
\hline None $(<5)$ & $24(17.1)$ & & \\
\hline Slight (5-9) & $90(64.3)$ & & \\
\hline Moderate (10-14) & $24(17.1)$ & & \\
\hline Severe $(\geq 15)$ & $2(1.4)$ & & \\
\hline
\end{tabular}

$\dagger$ median score 
Table 2. Dietary intake among participants

\begin{tabular}{|c|c|c|c|}
\hline Dietary Intake & Recommendation $^{+}$ & $n(\%)$ & Mean $\pm S D$ \\
\hline Total energy intake (kcal/day) & & & $1567 \pm 438$ \\
\hline Male & $2240 \mathrm{kcal} /$ day & & $1890 \pm 402$ \\
\hline$<2240$ & & 35 (89.7) & \\
\hline$\geq 2240$ & & $4(10.3)$ & \\
\hline Female & $1840 \mathrm{kcal} /$ day & & $1443 \pm 386$ \\
\hline$<1840$ & & $92(91.1)$ & \\
\hline$\geq 1840$ & & $9(8.9)$ & \\
\hline Dietary fibre intake (g/day) & 20-30 g/day & & $5.6 \pm 3.5$ \\
\hline$<20$ & & $100(100)$ & \\
\hline $20-30$ & & $0(0)$ & \\
\hline$>30$ & & $0(0)$ & \\
\hline Total fluid intake (ml/day) & $2000 \mathrm{ml} /$ day & & $2301 \pm 946$ \\
\hline$<2000$ & & $60(42.9)$ & \\
\hline$\geq 2000$ & & $80(57.1)$ & \\
\hline
\end{tabular}

${ }^{+}$Recommendation is based on RNI for Malaysians (NCCFN, 2017) for energy (at PAL 1.6) and fluid intakes; MDG (NCCFN, 2010) for dietary fibre intake.

Only $10.3 \%$ of males and $8.9 \%$ of females achieved the recommended nutrient intake (RNI) for energy intake. None of the participants met the minimum amount of dietary fibre intake, which is $20 \mathrm{~g}$ per day. Table 3 shows the association between age, dietary intake, and perceived stress with constipation among the participants. Factors associated with constipation were age $(p=0.007)$, dietary fibre $(p=0.044)$, fluid $(p=0.050)$, energy $(p=0.040)$, and perceived stress $(p<0.001)$. All these factors explained a significant amount of the variance in the occurrence of constipation $[F(6.133)=16.373, p<0.001$, $\left.R^{2}=0.425, R_{\text {Adjusted }}^{2}=0.399\right]$.

\section{DISCUSSION}

The present study found that more than half of the participants had slight constipation, followed by a small percentage of participants with no or moderate constipation, as well as severe constipation. This study demonstrated that socio-demographic characteristics, dietary intake, physical activity, and perceived stress were associated with constipation among the participants.

Table 3. Factors related to constipation among university students

\begin{tabular}{lcccccc}
\hline \multirow{2}{*}{ Model } & \multicolumn{2}{c}{$\begin{array}{c}\text { Unstandardised } \\
\text { Coefficients }\end{array}$} & $\begin{array}{c}\text { Standardised } \\
\text { Coefficients }\end{array}$ & $t$ & $p$ & 95\% CI \\
\cline { 2 - 6 } & Beta & $\begin{array}{c}\text { Std. } \\
\text { Error }\end{array}$ & Beta & & & \\
\hline Age & 0.354 & 0.129 & 0.191 & 2.744 & 0.007 & $(0.990,0.196)$ \\
Dietary fibre (mg) & -0.114 & 0.056 & -0.145 & -2.035 & 0.044 & $(-0.225,-0.003)$ \\
Fluid (ml) & 0.000 & 0.000 & -0.142 & -1.976 & 0.050 & $(-0.001,0.000)$ \\
Energy (kcal) & 0.001 & 0.000 & 0.149 & 2.074 & 0.040 & $(0.000,0.002)$ \\
Perceived stress scale & 0.291 & 0.036 & 0.561 & 7.999 & $<0.001$ & $(0.219,0.362)$ \\
\hline
\end{tabular}

$R^{2}=0.425$, Adj. $R^{2}=0.399 ; F=16.373, p<0.001$ 
Further analysis showed that the factors associated with constipation were age, dietary fibre, fluid, energy, and perceived stress.

According to a systematic review conducted by Mugie et al. (2011), the prevalence of constipation worldwide among the general population was very variable, with a range of $2.5 \%$ to $79.0 \%$ among adults. A study revealed that the prevalence of constipation was higher among hospitalised patients, their attendants, and medical students in the age group of 18 to 30 years old (Khatri et al., 2011). In comparison to the present study, most of the participants had slight constipation and a small percentage had severe constipation. A previous study by Lim et al. (2016) reported that the prevalence of constipation was higher than this present study, although it was conducted at the same university. This inconsistent finding may be due to the different target population and age range of participants, in which the previous study was conducted not only among undergraduate students, but involved participants between the age range of 18 to 30 years (Lim et al., 2016).

In the process of ageing, a lot of health changes can be observed and one of the changes is increased risk towards constipation. According to the American Gastroenterological Association (2013), the median overall prevalence of constipation was $16 \%$ in adults, with a rate of $33.5 \%$ in adults aged 60 to 101 years old in North America. In the present study, age was significantly associated with constipation scores among the participants. Gras-Miralles \& Cremonini (2013) addressed that increasing age was associated with a progressive increase in the risk of constipation. Furthermore, this finding was also supported by a study from Talley et al. (2003). They found a strong association between increasing age and the risk of chronic constipation among participants aged 11 to above 75 years old. Pelvic Floor Dysfunction (PFD) and slow colonic transit are two major aetiologies of constipation, of which those without any identified cause are classified as having normal transit constipation. Elasticity, compliance, altered macroscopic structural changes (example diverticulosis), and altered control of the pelvic floor are affected by age-related cellular dysfunctions. These molecular and physiologic changes are possible explanations for the association between age and constipation.

Only $10.3 \%$ of males and $8.9 \%$ of females achieved the RNI for energy intake. This finding was consistent with another cross-sectional study performed by Gan et al. (2011) where more than half of the Malaysian undergraduate students did not meet the RNI for total energy intake. Similarly, Mazlyn et al. (2013) reported that only $12.2 \%$ of Malaysian adults aged between 18 to 60 years old met the RNI for total energy intake. The present study revealed that total energy intake had a statistically significant correlation with constipation among undergraduate students. This finding was in contrast with another study by Bouchoucha et al. (2006), which reported that constipation is contributed by a low total calorie intake due to diminished gastrocolic reflex in response to eating. The gastrocolic reflex is a physiological reflex that controls the motility of the lower gastrointestinal tract following a meal. The colon will have increased motility in response to the stretch of the stomach on ingestion of food. The gastrocolic reflex allows room for consumption of more food via control over peristalsis and movement of ingested food distally towards the rectum. Thus, with limited amount of food intake, colon motility will decrease (Malone \& Thavamani, 2020).

However, in the present study, most of the participants did not achieve 
the energy requirement based on the RNI for Malaysia (NCFFN, 2017) and majority of them fell in the category of slightly constipated. Therefore, these two variables were positively associated. Another previous study showed that refined grains was a major food that causes constipation, as they have a low dietary fibre level that can lead to constipation (Mazlyn et al., 2013). Perhaps the participants in this present study may have consumed foods that are high in refined grains, which have caused a higher energy intake and increased risk of constipation. However, in this study, Food Frequency Questionnaire (FFQ) or Semi-food Frequency Questionnaire (SFQ) were not used, and therefore, there was a limitation to further investigate the link between refined grains intake and risk of constipation.

In the present study, the mean dietary fibre intake of the participants was low and all of them had a daily dietary fibre intake of $<20 \mathrm{~g}$. The finding was consistent with previous studies examining the status of fibre intake in Malaysians. An earlier study found that dietary fibre intake among Malaysian adults aged between 22 to 60 years was less than the recommended dietary fibre intake, which was between $10.0 \mathrm{~g}$ to $15.6 \mathrm{~g}$ (Ng et al., 2016). In the present study, lower dietary fibre intake also contributed to constipation. A study conducted by Khatri et al. (2011) among Malaysian adolescents, adults, and the elderly showed similar results in which there was a negative correlation between dietary fibre intake with constipation for all subjects combined. Alternatively, the higher the dietary fibre intake, the lower the risk of getting constipation. Increased dietary fibre can reduce the risk of getting constipation by increasing faecal bulk, defecation frequency and stool consistency, as well as reducing transit time of the faecal material through the large intestines.
The mean total fluid intake reported among the participants was $2301 \pm 946$ $\mathrm{ml}$ per day, and more than half of the participants in the present study $(57.1 \%)$ achieved the RNI for recommended total fluid intake of $2000 \mathrm{ml}$ per day. There was an inverse correlation between total fluid intake and constipation. This result was consistent with a previous study by Khatri et. al. (2011), which found that total fluid intake was negatively correlated with constipation. In other words, as fluid consumption increases, the risk of constipation decreases. This is because adequate fluid intake can facilitate dietary fibre to increase the weight of stool and produce soft stools.

In the present study, majority of the participants had stress levels ranging from moderate to very high. These findings were not in agreement with a previous study conducted among undergraduate students (Mikolajczyk et al., 2009), which indicated that only $21.6 \%$ of undergraduate students experienced moderate to high levels of stress. Apart from academic overload, it was found that stress levels among university students increased due to other factors as well such as personal problems, financial problems, college activities and others (Rahim et al., 2016). Based on a study conducted by Bataineh (2013), it was suggested that a high level of stress among undergraduate students was due to several reasons such as a heavy academic workload, low motivation, and competition with other students, meeting with failures, high family expectations, and lack of purchasing power.

A positive correlation was found between stress scores and constipation scores among the participants. This finding from the current study was in line with an earlier study which reported depression and stress as being statistically, significantly correlated with abnormal anorectal function, 
indicating that a higher stress level may contribute to functional constipation (Leung et al., 2011). Similar finding was suggested in another study, where there was a statistically significant association between perceived stress level and constipation symptoms among 715 nursing students in Korea (Lee et al., 2011). Disturbances of the gastrointestinal tract function may occur due to stress, thus increasing the risk of getting constipation (Suzana et al., 2009).

It was proven that the risk of chronic constipation was decreased significantly by doing regular physical activity (Chang et al., 2015). A systematic review by Peters, De Vries, VanbergeHenegouwen \& Akkermans (2001) found that gastrointestinal diseases can be prevented by doing regular physical activity at a relatively low intensity. However, in the present study, physical activity did not significantly contribute to constipation. The level of physical activity would be expected to increase the level of fluids required by the body, and dehydration may explain why higher levels of physical activity could be associated with more severe constipation since fluid intake in the body appear to be inadequate (Mazlyn et al., 2013). In the present study, more than half of the participants achieved the recommended fluid intake even though they were not physically active. Therefore, physical activity in the present study was not one of the contributing factors as most of them had low to moderate levels of physical activity and consumed enough fluids.

There were several limitations in the present study that should be taken into consideration. The cross-sectional design of the present study has limited its findings from showing the causal relationship between the dependent and independent variables, although multivariate analysis was used to determine these factors. All data were self-reported by the participants via selfadministered questionnaires, which was highly dependent on the honesty and memory of the participants, especially on questions relating to physical activity and stress levels. As a result, this can lead to reporting bias. Another important limitation was the unavailability of anthropometry data to strengthen the results, such as to capture the issue of under-reporting (UR). This is because the present study did not measure anthropometric metrics, which led to the inability to calculate basal metabolic rate that is vital to address UR.

Another important limitation that needs to be addressed is the limitation associated with the Agachan's Constipation Score System Questionnaire, which was used to assess the prevalence and severity of constipation. It had several categories to classify the severity of constipation, but this questionnaire required a score of more than 15 to meet the definition of "constipation". According to this classification, only two participants were identified as having constipation. Therefore, Multiple Logistic Regression (MLR) was not performed.

It was noted that in the present and previous studies, there are several risk factors of getting constipation, which include low total energy intake, low dietary fibre intake, low water intake, physical inactivity, and stress (Leung et al., 2011). But, in real life, people consume mixed foods that contain various nutrients instead of certain foods or single nutrients. Dietary pattern is a dynamic state that takes into account the interactions and intercorrelations between nutrients and foods, as well as their cumulative effects on health. Therefore, it is recommended that future studies focus on dietary pattern in relation to constipation among university students. Besides 
that, the present study only recruited undergraduate students from UPM, which may limit the generalisability of the study. Hence, future studies are recommended to involve students from different universities in Malaysia in order for the study findings to be generalised to all university students in the country.

\section{CONCLUSION}

Age, energy, fluid and fibre intakes, as well as perceived stress were factors that were associated with constipation among undergraduate students. Therefore, undergraduate students should be encouraged to consume adequate energy, dietary fibre, and fluids in their daily life. On top of that, they also require attention from various parties, especially counsellors in universities, as well as health care professionals to assist them to reducing their stress levels.

\section{Acknowledgement}

We would like to thank all the participants and the people who contributed to the success of this study.

\section{Authors' contributions}

NBMY, principal investigator, conceptualised and designed the study, led the data collection, prepared the draft of the manuscript and reviewed the manuscript; QAMY, conducted data analysis, assisted in drafting of the manuscript and reviewed the manuscript.

\section{Conflicts of interest}

The authors report no conflicts of interest.

\section{References}

American Gastroenterological Association, Bharucha AE, Dorn SD, Lembo A \& Pressman A (2013). American Gastroenterological Association medical position statement on constipation. Gastroenterology 144(1):2117. doi: 10.1053/j.gastro.2012.10.029. PMID: 23261064

Bataineh MZ (2013). Academic stress among undergraduate students: the case of education faculty at King Saud University. Int Interdiscip $J$ Educ 2(1):82-88.
Bouchoucha M, Devroede G, Faye A, Le Toumelin P, Arhan P \& Arsac M (2006). Colonic response to food in constipation. Int $J$ Colorectal Dis 21:826-833.

Chang LL, Lin YC, Lo TC, Chen MC \& Kuo HW (2015). Understanding the lifestyle correlates with chronic constipation and self-rated health. Food Nutr Sci 6(4):391-398. https:// doi.org/10.4236/fns.2015.64040

Gan WY, Mohd Nasir MT, Zalilah MS \& Hazizi AS (2011). Disordered eating behaviors, depression, anxiety and stress among Malaysian University students. Coll Stud J 45(2):296-309.

Gras-Miralles B \& Cremonini F (2013). A critical appraisal of lubiprostone in the treatment of chronic constipation in the elderly. Clin Interv Aging 8:191-200. doi:10.2147/CIA.S30729

Health Promotion Board Singapore (2003). Food Composition Guide Singapore. Health Promotion Board, Singapore.

IPH (2020). National Health and Morbidity Survey (NHMS) 2019: non-communicable diseases, healthcare demand, and health literacy-Key Findings. Institute for Public Health, Ministry of Health Malaysia.

International Physical Activity Questionniare Group (2002). International Physical Activity Questionnaire: Short Last 7 days selfadministered format for use with young and middle aged adults. From www.ipaq.ki.se [Retrieved May 15 2021]

Karakaya iÇ, Kılıç Z, Yılmaz Ü \& Karakaya MG (2015). Üniversite öğrencilerinde konstipasyon problemi ve fiziksel aktivite düzeyi ilişkisi. TAF Prev Med Bull 14(4):329-332. https://doi. org/10.5455/pmb.1-1427885590

Khatri PK, Ali AD, Alzadjali N, Bhagia G, Khaliqdina SJ \& Aziz S (2011). Frequency of functional constipation in 3 different populations and its causative factors. JPMA. J Pak Med Assoc 61(11):1149-1152.

Koo HC, Hadirah Z, Airina A, Nurul Alifatul Amrina R \& Faziela N (2019). Effect of nutrient intakes on anthropometric profiles among university studentfrom a selected private university in Klang valley, Malaysia. Afr Health Sci 19(2):2243-2251. https://doi.org/10.4314/ ahs.v19i2.50

Lee EY, Mun MS, Lee SH \& Cho HSM (2011). Perceived stress and gastrointestinal symptoms in nursing students in Korea: A cross-sectional survey. BMC Nursing 10(1):1. doi: 10.1186/14726955-10-22 
Leung L, Riutta T, Kotecha J \& Rosser W (2011). Chronic constipation: an evidence-based review. J Am Board Fam Med 24(4):436-451.

Lim YJ, Rosita J, Chieng JY \& Hazizi AS (2016). The prevalence and symptoms characteristic of functional constipation using Rome III diagnostic criteria among tertiary education students. PloS one 11(12):e0167243. https:// doi.org/10.1371/journal.pone.0167243

Lingu I, Kulkarni PV, Tanna I \& Chandola HM (2012). Evaluation of diet, life style and stress in the etiopathogenesis of constipation in geriatric people. Int $J$ Res Ayurveda Pharm 3(6):879-883. http://doi.org/10.7897/22774343.03643

Malone JC \& Thavamani A (2020) Physiology, Gastrocolic Reflex (Gastrocolic Response). Stat Pearls Publishing, Treasure Island (FL).

Mazlyn MN, Lee HL, Fatimah A, Norimah AK \& Goh KL (2013). Stool Patterns of Malaysian Adults with Functional Constipation: Association with Diet and Physical Activity. Mal $\mathrm{J}$ Nutr 19(1):53-64.

Mikolajczyk RT, El Ansari W \& Maxwell AE (2009). Food consumption frequency and perceived stress and depressive symptoms among students in three European countries. Nutr $J$ 8(1):31. http://doi.org/10.1186/1475-28918-31

Mugie S, Benninga C \& Di Lorenzo M (2011). Epidemiology of constipation in children and adults: A systematic review. Best Pract Res Clin Gastroenterol 25(1):3-18. http://doi. org/10.1016/j.bpg.2010.12.010

NCCFN (2010). Malaysian Dietary Guidelines. National Coordinating Committee on Food and Nutrition, Ministry of Health Malaysia, Kuala Lumpur.

NCCFN (2017). Recommended Nutrient Intakes for Malaysia. National Coordinating Committee on Food and Nutrition, Ministry of Health Malaysia, Kuala Lumpur.

Ng TKW, Jia YT, Low YO, Yeoh LZW \& Gan CL (2016). Dietary fibre and total fluid intakes are inversely associated with risk of constipation in Malaysian adolescents, adults and the elderly. IeJSME 10(1):17-23.
Patimah AW, Lee YY \& Dariah MY (2017). Frequency patterns of core constipation symptoms among the Asian adults: A systematic review. BMC Gastroenterol 17(1):1-12. https://doi. org/ 10.1186/s 12876-017-0672-z

Peters HPF, De Vries WR, Vanberge-Henegouwen GP \& Akkermans LMA (2001). Potential benefits and hazards of physical activity and exercise on the gastrointestinal tract. Gut 48(3):435-439.

Rahim MSA, Saat NZM, Aishah HS, Arshad SA, Aziz NAA, Zakaria NN, Kaur K, Kamaruddin MM \& Suhaimi NHF (2016). Relationship between academic workload and stress level among biomedical science students in Kuala Lumpur. J Appl Sci 16(3):108-112. https:/ / doi. org/10.3923/jas.2016.108.112

Salamudin N \& Harun MT (2013). Physical activity index among Malaysian youth. Asian Social Science 9(12 SPL ISSUE): 99-104. https://doi. org/10.5539/ass.v9n12p99

Sogari G, Velez-Argumedo C, Gómez MI \& Mora C (2018). College students and eating habits: A study using an ecological model for healthy behavior. Nutrients 10(12):1-16. https://doi. org/10.3390/nu10121823

Suzana S, Noor Aini MY, Nik Shanita S, Rafidah G \& Roslina A (2009). Atlas of Food Exchanges and Portion Sizes (2 ${ }^{\text {nd }}$ Edition). Kuala Lumpur: MDC Publishers Sdn. Bhd.

Talley NJ, Jones M, Nuyts G \& Dubois D (2003). Risk factors for chronic constipation based on a general practice sample. Am J Gastroenterol 98(5):1107-11.

Tee ES, Ismail MN, Mohd Nasir A \& Khatijah I (1997). Nutrient Composition of Malaysian Foods (4th Edition). Malaysian Food Composition Database Programme. Institute for Medical Research, Kuala Lumpur. 